\title{
Origin of the Recrystallization Texture Formation in an Interstitial Free Steel
}

\author{
Yasunobu NAGATAKI and Yoshihiro HOSOYA \\ Materials \& Processing Research Center, NKK Corporation, Kokan-cho, Fukuyama, Hiroshima-ken, 721 Japan.
}

(Received on September 12, 1995; accepted in final form on November 29, 1995)

\begin{abstract}
A laboratory investigation has been carried out to reveal the mechanism of recrystallization texture formation in an interstitial free (IF) steel, based on the assumption that the reduced grain boundary constraint for a grain rotation during cold-rolling plays an important role on the mechanism. As a parameter of grain boundary constraint, the ratio of deformation strengths of grain boundary area and grain matrix were varied by changing the cold-rolling temperature $\left(-100-200^{\circ} \mathrm{C}\right)$ and microalloying of boron into IF steel. The paper revealed that the reduced grain boundary constraint by scavenging the interstitial elements from grain boundaries not only enhanced a development of $\gamma$-fiber texture but also suppressed a formation of deformation bands inside the $\gamma$-fiber matrix during cold-rolling in IF-steel. In-situ like recrystallization from the strong $\{111\}\langle 112\rangle$ $\gamma$-fiber texture, which is caused by a reduction of nucleation frequency of $\langle 110\rangle / / N D$ grains from deformation bands, is the origin of the the strong $\{111\}\langle 112\rangle \gamma$-fiber recrystallization texture formation in IF steel.
\end{abstract}

KEY WORDS: interstitial free steel; cold-rolling; recrystallization texture; grain boundary constraint; metallography.

\section{Introduction}

During a last decade, interstitial free (IF) steel has become indispensable to provide a customer with an entire non-aging steel sheet by converting the annealing process from batch annealing to continuous annealing. Since IF steel is a unique type of steel which combines superior formability with non-aging properties, a number of steel researchers have been taking a deep interest in it from a view point of not only industrial applications but also physical metallurgy. ${ }^{1-3)}$ In particular, regarding a sudden change in the $r$-value by microalloying of carbonitrides forming elements such as $\mathrm{Ti}, \mathrm{Nb}$ and $\mathrm{Zr}$ etc. on the stoichiometric basis to the interstitial elements in solution, physical metallurgists grappled with interpreting the substantial mechanism of this phenomenon so far. ${ }^{4-10)}$ Early investigations had been carried out based on the growth selection model with paying attention to the effect of either the critical dispersion of carbonitrides ${ }^{5,79}$ or the presence of carbonitrides forming elements in solution. ${ }^{6)}$ At present, however, these mechanisms seem unlikely to be correct since continuous annealing process with rapid heating rate hardly deteriorate the $r$-value of IF steel. Consequently, scavenging mechanism, which emphasizes the purification of an iron matrix by removing the interstitial elements, has come to the front. ${ }^{8,10)}$ However, the origin of the sudden change of the recrystallization texture (development of $\{111\}\langle 112\rangle$ texture) at the stoichiometric composition can not be interpreted even by the mechanism of purifying the iron matrix, because 1.8 was the at most the mean $r$-value of unalloyed steel with the carbon content of nearly zero reached even if the difference in grain size of hot-band is taken into consideration. ${ }^{11,12)}$

Regarding the recrystallization texture formation of cold-rolled polycrystalline materials, inhomogeneities of deformation strain and stored-energy accumulated in each grain during cold-rolling play important roles. In the IF steel, prime factor which originates the inhomogeneity is considered to be grain boundary constraint for grain rotation during cold-rolling. IF steel is distinguished from other steels with respect to the absence of carbon at grain boundaries, the cohesion of which are increased by segregation of carbon during annealing even in the $\alpha$-iron with 8 ppm carbon. ${ }^{13)}$ Since the small amount of $\mathrm{C}$ or $\mathrm{N}$ greatly increase $k$ in the Hall-Petch equation $\left(\sigma=\sigma_{0}+k d^{-1 / 2}\right),{ }^{14)}$ disappearance of these elements from grain boundaries at the transition from deficient to excessive regarding the stoichiometric composition prompted us the scavenging of interstitial elements from the grain boundaries weaken the grain boundary constraint for subgrain formation during cold-rolling through a reduction in grain boundary strength.

The purpose of the present paper is to corroborate the mechanism that the marked development of $\gamma$-fiber recrystallization texture in the IF steel originates from the homogeneous subgrain structure which was developed by the reduction of grain boundary constraint caused by the scavenging of interstitial elements from grain boundaries. 


\section{Experimental Procedure}

Ti bearing IF steel (Ti-IF steel) was used as a base material. Ti and boron bearing IF steel (Ti, B-IF steel) and low carbon aluminum-killed steel (low $\mathrm{C}$ steel) were also used as the materials of which grain boundaries were strengthened by boron and carbon in solution. These steels were industrially hot-rolled to $2.8 \mathrm{~mm}$ thick with following conditions. Ti-IF and Ti, B-IF steels: SRT (slab reheat temperature) $=1200^{\circ} \mathrm{C}, \mathrm{FT}$ (finishing temperature) $=890^{\circ} \mathrm{C}, \mathrm{CT}$ (coiling temperature) $=620^{\circ} \mathrm{C}$, Low C steel: $\mathrm{SRT}=1200^{\circ} \mathrm{C}, \mathrm{FT}=870^{\circ} \mathrm{C}, \mathrm{CT}=700^{\circ} \mathrm{C}$. Chemical compositions of these steels are shown in Table 1.

After pickling, hot-bands were cold-rolled to $0.8 \mathrm{~mm}$ thick with $70 \%$ reduction by laboratory mill. Regarding the cold-rolling, we carried it out at $-100,0,100$ and $200^{\circ} \mathrm{C}$ based on a prediction as shown in Fig. 1 to vary the ratio of the deformation strengths of grain boundary and grain matrix as the parameter of grain boundary constraint. Lower and upper limits in rolling temperature are set to avoid an embrittlement and a dynamic interaction of interstitial elements and dislocation, respectively. Slip systems seem to be hardly changed within the temperatures investigated from the result that $n$-value of steel sheet hardly changes below $\left.200^{\circ} \mathrm{C} .{ }^{15}\right)$ In order to eliminate the effect of heat generated by rolling, samples were held in a thermostatic bath for every intervals of rolling and the reduction of each pass was limited lower than $6 \%$.

Cold-rolled sheets were annealed at $660-840^{\circ} \mathrm{C}$ for $90 \mathrm{sec}$ in the salt bath followed by air-cooling. Both cold-rolling texture and recrystallization texture were assessed by the $\mathrm{X}$-ray integrated intensities of $\langle 111\rangle / /$ $\mathrm{ND},\langle 100\rangle / / \mathrm{ND},\langle 211\rangle / / \mathrm{ND}$ and $\langle 110\rangle / / \mathrm{ND}$ fiber

Table 1. Chemical compositions of steels used. (mass\%)

\begin{tabular}{llcccccccc}
\hline No. & C & Si & Mn & P & S & sol.Al & N & Ti & B \\
\hline 1 & 0.0029 & 0.01 & 0.15 & 0.012 & 0.008 & 0.025 & 0.0029 & 0.07 & - \\
2 & 0.0018 & 0.02 & 0.17 & 0.014 & 0.008 & 0.045 & 0.0019 & 0.04 & 0.0006 \\
3 & 0.025 & 0.01 & 0.21 & 0.011 & 0.007 & 0.050 & 0.0019 & - & - \\
\hline
\end{tabular}

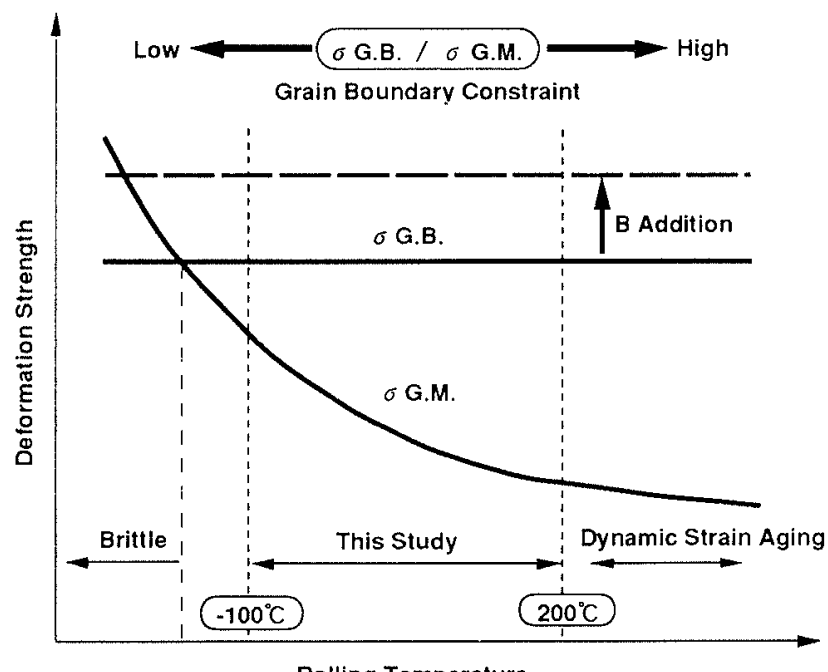

Rolling Temperature

Fig. 1. Schematic diagram showing the principles of this study regarding the cold-rolling conditions. textures and the $\{100\}$-pole figures. Optical microscopic and scanning electron microscopic (SEM) observations were performed through cross section on longitudinal and transversal directions.

Deformation strengths ratio of grain boundary area $\left(\sigma_{\mathrm{GB}}\right)$ and grain matrix $\left(\sigma_{\mathrm{GM}}\right)$ in each cold-rolling temperature were evaluated as a function of grain size. According to the Hall-Petch equation, hardness of polycrystalline material is composed of two terms of deformation resistance of grain boundary and grain matrix as shown in Eq. (1).

$$
H v=A \times d^{-1 / 2}+B
$$

From the Vickers hardness value of the materials with different grain size measured at different temperature, each term can be evaluated. For this evaluation, hotbands with coarse grain structure were prepared by soaking at $840^{\circ} \mathrm{C}$ (Ti-IF), $900^{\circ} \mathrm{C}(\mathrm{Ti}, \mathrm{B}-\mathrm{IF})$ and $800^{\circ} \mathrm{C}$ (low C) for $30 \mathrm{~min}$ after temper-rolling with $8 \%$ reduction. The load in the $H v$ measurement was $10 \mathrm{kgf}$, so the deformed area included grain boundaries even in the coarse grain samples. As the parameter of relative grain boundary constraint, we used $\left(A \times d^{-1 / 2}\right) / B$.

\section{Results and Discussion}

\subsection{Evaluation of the Strength of Grain Boundary Constraint}

As a key factor of this investigation, we evaluated the strength of grain boundary constraint by a ratio of $\sigma_{\mathrm{GB}}$ and $\sigma_{\mathrm{GM}}$ in each cold-rolling temperature according to the prediction shown in Fig. 1. Figure 2 shows the Vickers hardness $(H v)$ change of the hot-bands with different grain size as a function of temperature. Within the limits of testing temperature, $\mathrm{Hv}$ of each steel changes with dependence on grain size, steel chemistry and temperature. Subsequently, we replotted the $H v$ as a function of $d^{-1 / 2}$ as shown in Fig. 3. From Fig. 3, we evaluated $A$ and $B$ in Eq. (1) with the slope and the intercept of each line, respectively.

Figure 4 shows the change in the parameters $A \times d^{-1 / 2}$, $B$ and $\left(A \times d^{-1 / 2}\right) / B$ as a function of temperature in

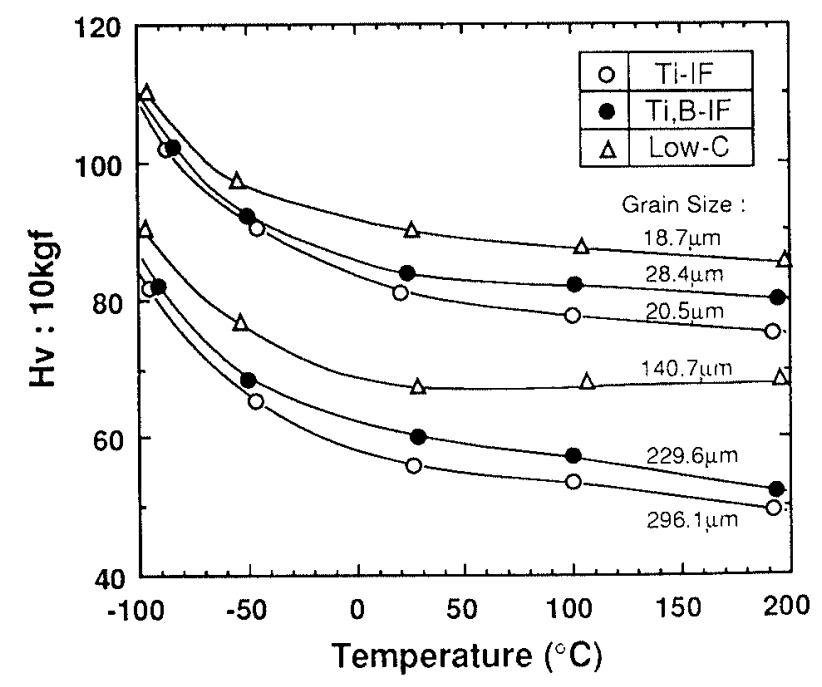

Fig. 2. Vickers hardness $(H v)$ change of the hot-bands with different grain size as a function of temperature. 


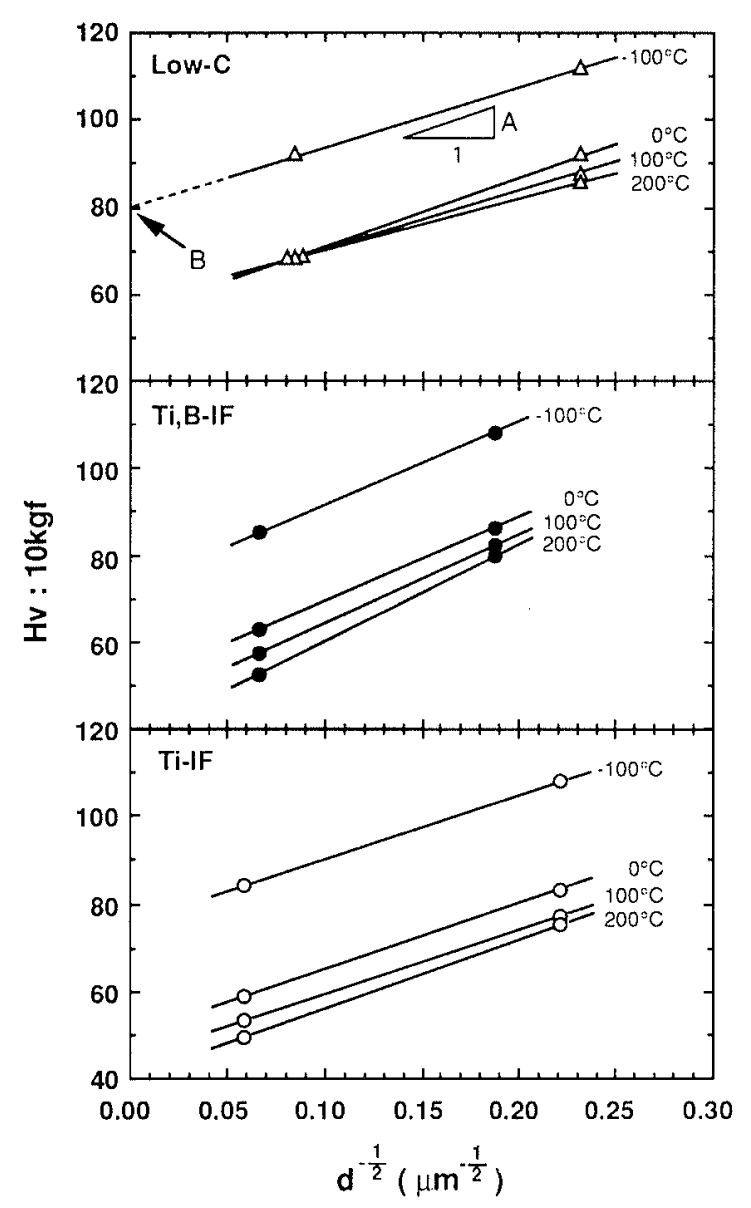

Fig. 3. Change in $H v$ as a function of $d^{-1 / 2}$ for different temperature.

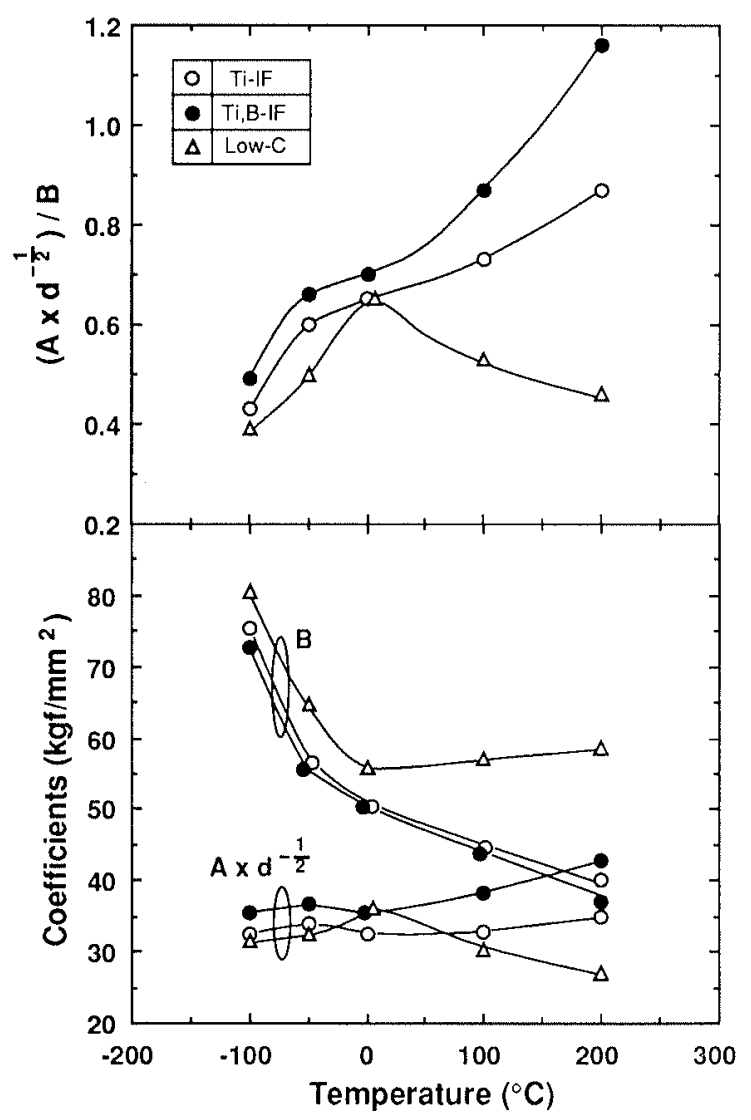

Fig. 4. Change in the parameters $A \times d^{-1 / 2}, B$ and $(A \times$ $\left.d^{-1 / 2}\right) / B$ as a function of temperature in steels-1 to 3 . steels-1 to 3 . In accordance with the prediction shown in Fig. $1, B$ decreases with elevating the temperature while the dependency of $A \times d^{-1 / 2}$ on the temperature is small. In the IF steels, $\left(A \times d^{-1 / 2}\right) / B$ increases with elevating the temperature. In case of low $C$ steel, however, $B$ slightly increases with elevating the temperature from about room temperature (R.T.) up after decreased with elevating the temperature similarly to the IF steels up to about R.T.

Corresponding to the change in $B, A \times d^{-1 / 2}$ slightly decreases with elevating the temperature from about R.T. up. As a result of changes in $B$ and $A \times d^{-1 / 2}$, $\left(A \times d^{-1 / 2}\right) / B$ reaches a peak at about R.T. The peculiar change in $B$ and $A \times d^{-1 / 2}$ above the ambient temperature in low $C$ steel is considered to be caused by a dynamic interaction of solute $\mathrm{C}$ and dislocation.

\subsection{Cold-rolling Texture Formation with Different Rolling Temperature}

Figure 5 shows the change in the $\mathrm{X}$-ray integrated intensities of $\langle 111\rangle / / \mathrm{ND},\langle 100\rangle / / \mathrm{ND},\langle 211\rangle / / \mathrm{ND}$ and $\langle 110\rangle / / N D$ fiber textures as a function of cold-rolling temperature in steels-1 to 3. Marked difference in the cold-rolling texture between IF steels and low $\mathrm{C}$ steel is the levels of $\langle 111\rangle / / \mathrm{ND}$ and $\langle 100\rangle / / \mathrm{ND}$ fiber textures. With respect to the dependency of cold-rolling texture on the cold-rolling temperature, the intensities of <11 $>/ / N D(\gamma$-fiber) texture decrease with elevating the cold-rolling temperature in the IF steels, while it increases vice versa in the low $\mathrm{C}$ steel. Microalloying of boron enhances the reduction of the intensity of $\gamma$-fiber texture. The $\langle 110\rangle / / \mathrm{ND}$ fiber texture conversely increases with elevating the cold-rolling temperature in the IF steels. Microalloying of boron also enhances this tendency.

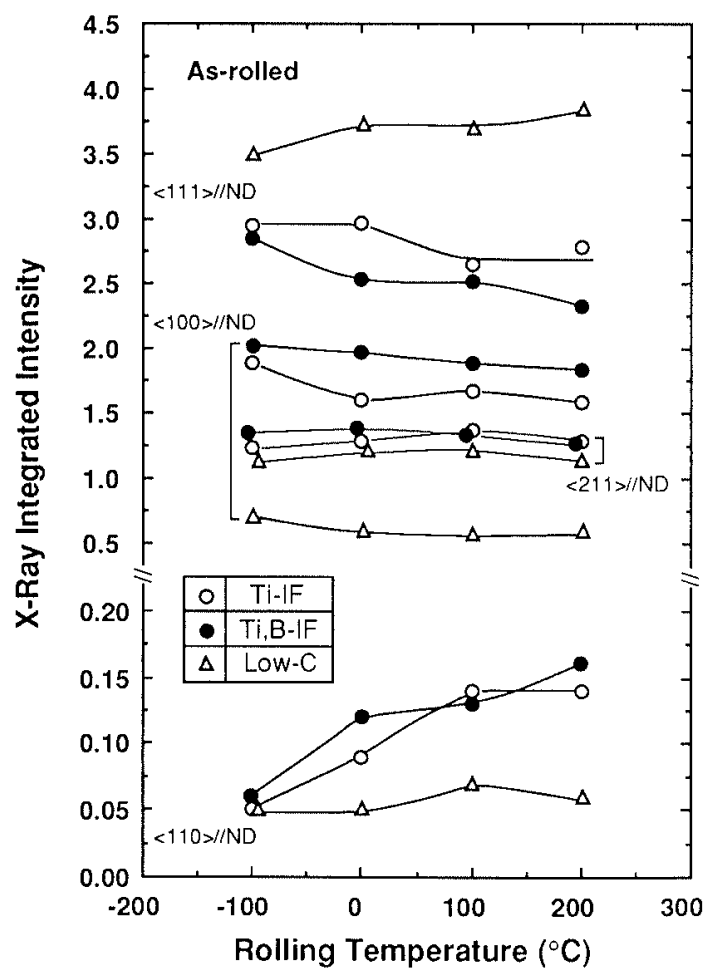

Fig. 5. Change in the $\mathrm{X}$-ray integrated intensities of $\langle 111\rangle / / \mathrm{ND},\langle 100\rangle / / \mathrm{ND},\langle 211\rangle / / \mathrm{ND}$ and $\langle 110\rangle / / \mathrm{ND}$ fiber textures as a function of cold-rolling temperature. 


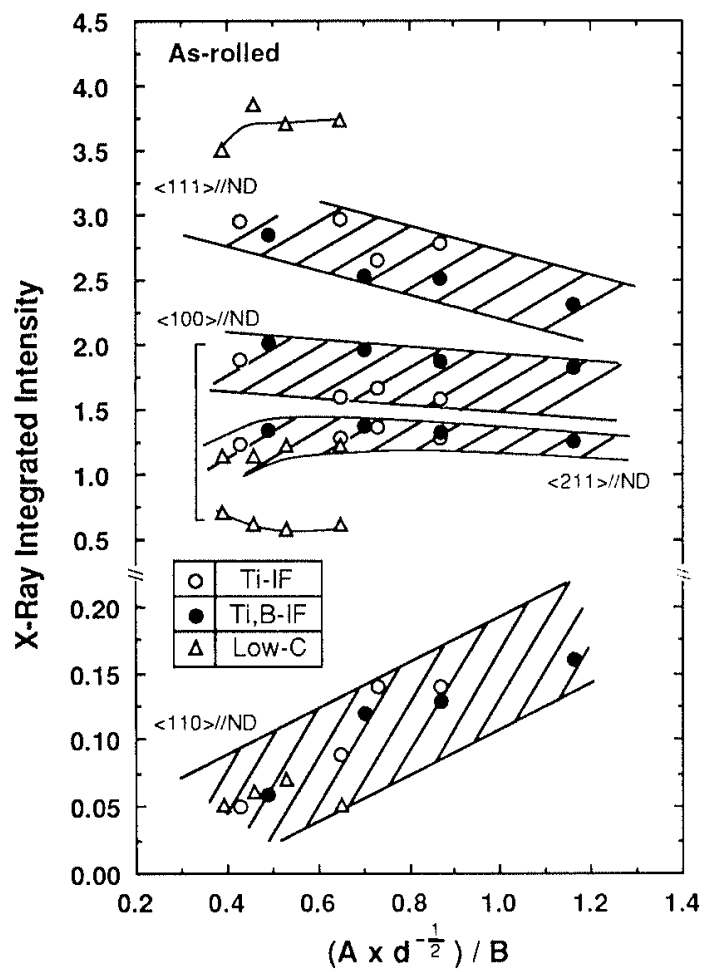

Fig. 6. Correlation between the parameter of $\left(A \times d^{-1 / 2}\right) / B$ and intensities of $\langle 11 \mathrm{I}\rangle / / \mathrm{ND},\langle 100\rangle / / \mathrm{ND},\langle 211\rangle / / \mathrm{ND}$ and $\langle 110\rangle / / \mathrm{ND}$ fiber textures.

Regarding the low $\mathrm{C}$ steel, the dependency of $\langle 110\rangle / / \mathrm{ND}$ fiber texture on the cold-rolling temperature is relatively small. The intensity of $\langle 211\rangle / /$ ND fiber texture depends on neither steel chemistry nor cold-rolling temperature.

Figure 6 shows the correlation between $\left(A \times d^{-1 / 2}\right) / B$ and each fiber texture. It can be observed that the intensity of $\langle 110\rangle / / \mathrm{ND}$ fiber texture increases and that of $\gamma$-fiber texture decreases vice versa with increase in $\left(A \times d^{-1 / 2}\right) / B$ in the IF steels. Dependency of $\langle 211\rangle / / \mathrm{ND}$ and $\langle 100\rangle / / \mathrm{ND}$ components on $\left(A \times d^{-1 / 2}\right) / B$ are relatively small. In the low $\mathrm{C}$ steel, clear correlation between each component and $\left(A \times d^{-1 / 2}\right) / B$ is hardly observed because $\left(A \times d^{-1 / 2}\right) / B$ could not be changed widely. This results suggest the strengthening of grain boundary constraint during cold-rolling enhances the formation of deformation bands (D.B.) having $\langle 110\rangle / /$ ND components inside the deformed matrix having $\langle 111\rangle / / \mathrm{ND}$ component.

Figure 7 shows the typical $\{100\}$-pole figures of steels-1 to 3 cold-rolled at $0^{\circ} \mathrm{C}$. Cold-rolling textures of every steels are composed of $\{111\}\langle 112\rangle,\{111\}\langle 110\rangle$, $\{211\}\langle 011\rangle$ and $\{100\}\langle 011\rangle$ components. In particular, microalloying of boron into IF steel enhances the development of $\langle 110\rangle / / R D$ ( $\alpha$-fiber) texture which includes $\{211\}\langle 011\rangle$ component as same as the effects of $\mathrm{Nb}, \mathrm{Ti}$ and $\mathrm{P}$ on enhancing the development of cold-rolling texture. ${ }^{16)}$

In order to demonstrate the effect of grain boundary constraint on the D.B. formation in Ti-IF steel, deformed structure by 30 and $50 \%$ reduction were observed by a optical microscopy after etched by nital etchant. Results are depicted in Fig. 8. Fraction of dark etched grains with slip-lines (or fishbone structure) increases with not

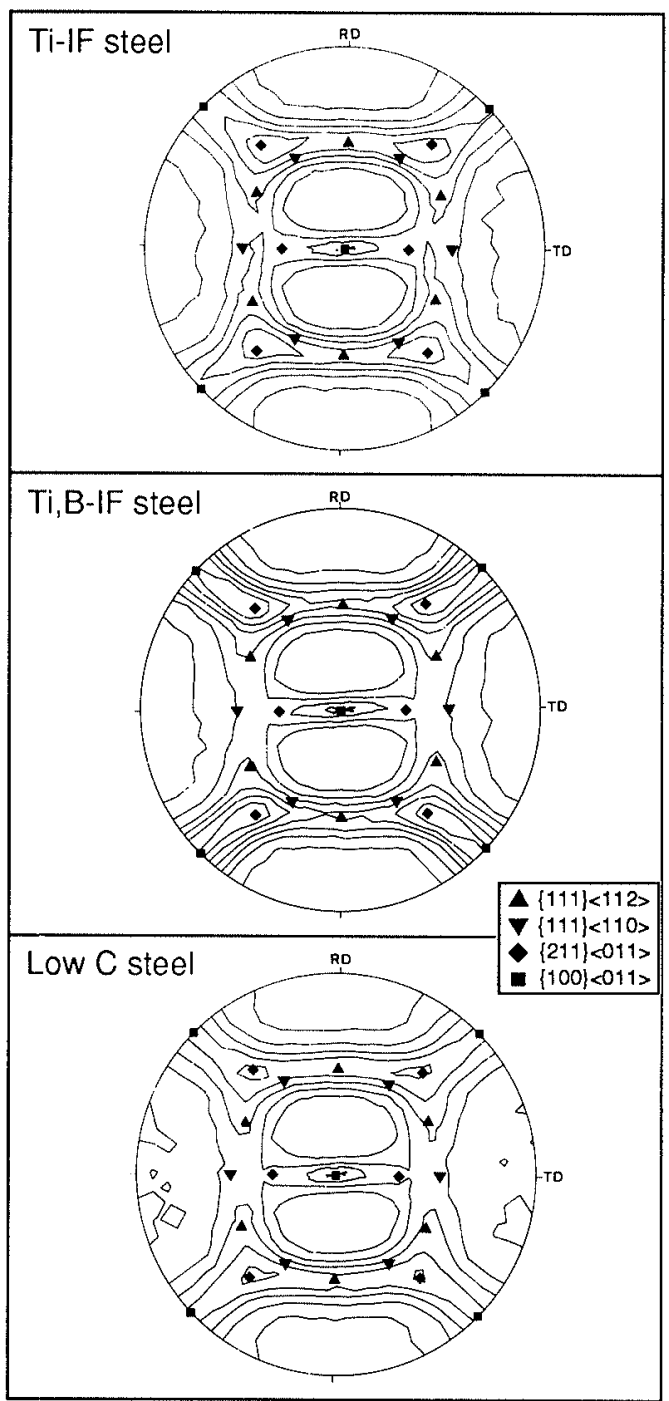

Fig. 7. Typical $\{100\}$-pole figures of steels- 1 to 3 cold-rolled at $0^{\circ} \mathrm{C}$.

only high reduction but also elevating the cold-rolling temperature up to $200^{\circ} \mathrm{C}$, i.e. strengthening the relative grain boundary constraint. As Vanderschueren pointed out, ${ }^{17)}$ these grains are considered to be the grains with strongly developed subgrain structure, namely $\gamma$-fiber grain and $\{110\}\langle 110\rangle$ grain. From these optical micrographs, it was clarified that the cold-rolling with the temperature between -100 and $200^{\circ} \mathrm{C}$ is dominant for the D.B. formation in the $\gamma$-fiber matrix through a change in the strength of grain boundary constraint.

Subsequently, the effects of small amounts of boron and carbon segregated at grain boundaries on the development of deformed structure are shown in Fig. 9 regarding the samples cold-rolled up to 30 and $50 \%$ at $0^{\circ} \mathrm{C}$. Comparing these micrographs with those of Ti-IF steel cold-rolled by same condition, it is clarified that the fractions of dark etched grains increase with presence of boron and carbon at grain boundaries.

Figure 10 shows the SEM micrographs observed at a transversal cross section of each steel cold-rolled in the conditon of $70 \%$ reduction and cold-rolling temperature of $0^{\circ} \mathrm{C}$, which demonstrate the effects small amounts of boron and carbon segregated at grain boundaries on the microstructural inhomogeneity in deformed matrix. In 


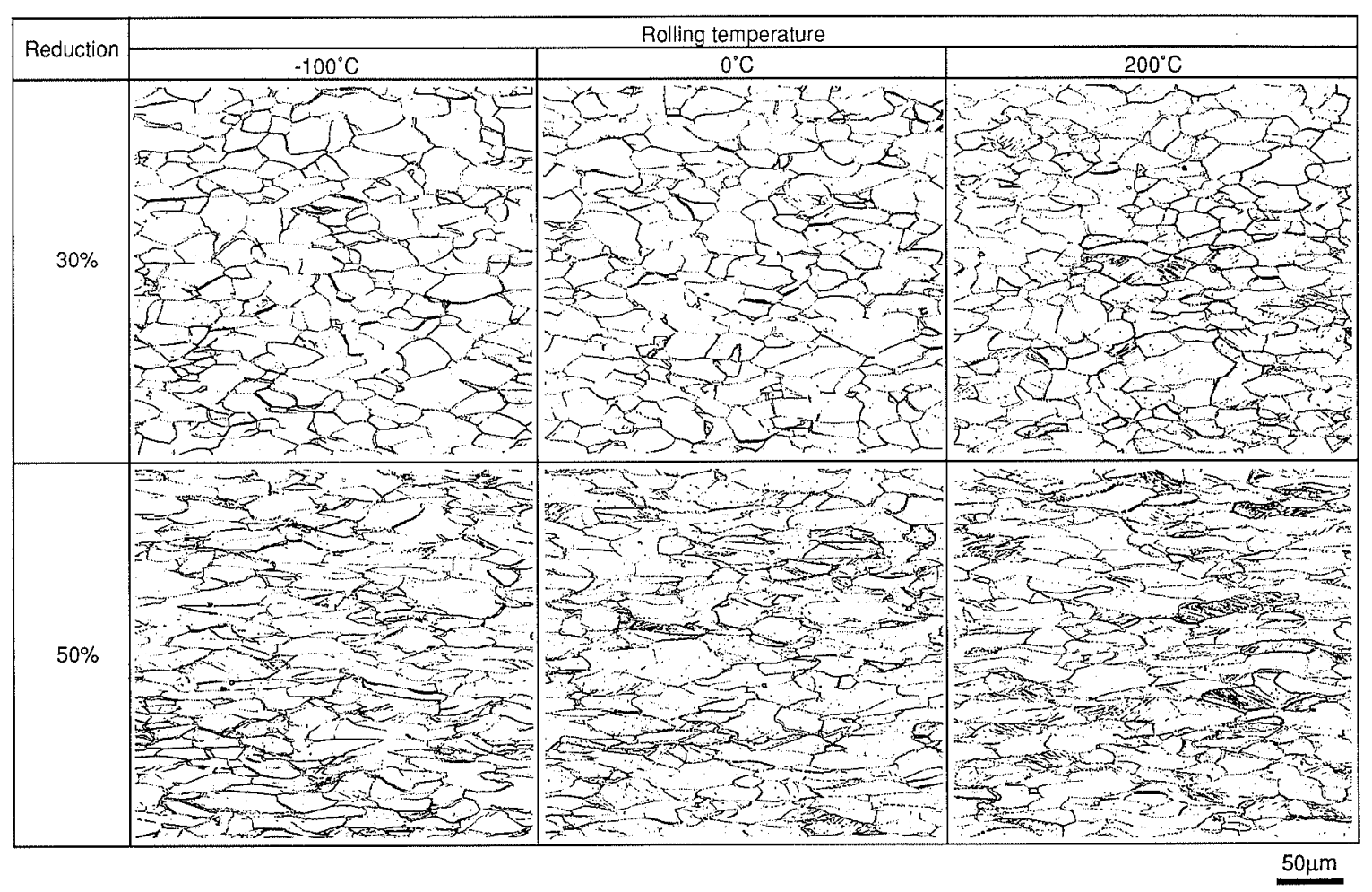

Fig. 8. Optical micrographs showing the effects of cold-rolling reduction and temperature on a development of deformed structure in Ti-IF steel.

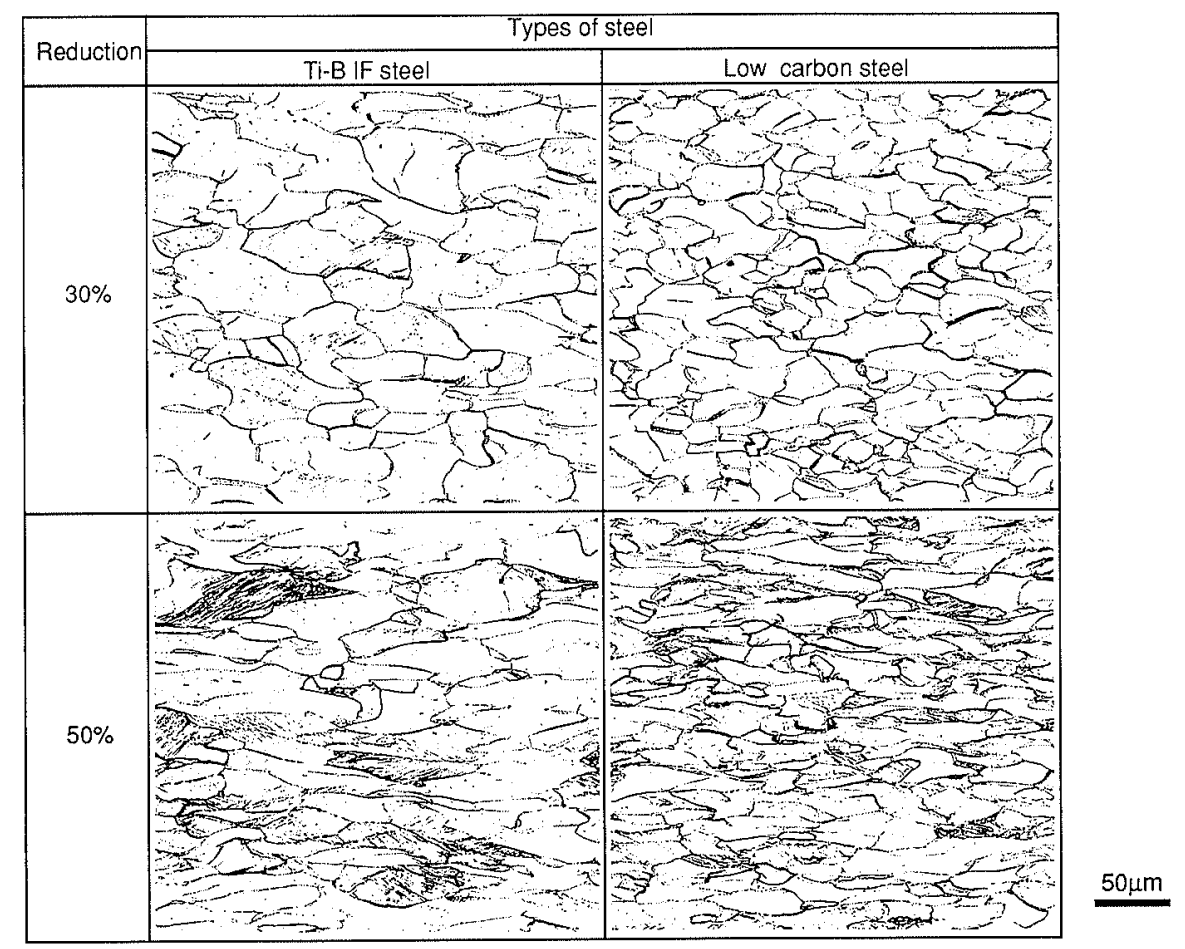

Fig. 9. Optical micrographs showing the effects of small amounts of boron and carbon segregated at grain boundaries on the development of deformed structure of the samples cold-rolled at $0^{\circ} \mathrm{C}$ up to 30 and $50 \%$.

both Ti, B-IF steel and low $\mathrm{C}$ steel, a number of microvoids are observed at grain boundaries while such microvoids are scarcely observed in Ti-IF steel. In the low $\mathrm{C}$ steel, microcracks are also observed at a interface of coarse cementite and ferrite grain. These microvoids enhanced by nital etching are considered to be generated at the misfits along the grain boundary, which indicates a highly deformed area during cold-rolling. Microstructure of Ti-IF steel prompts us that it is likely deformed homogeneously independent of the heterogeneity of microstructure. 


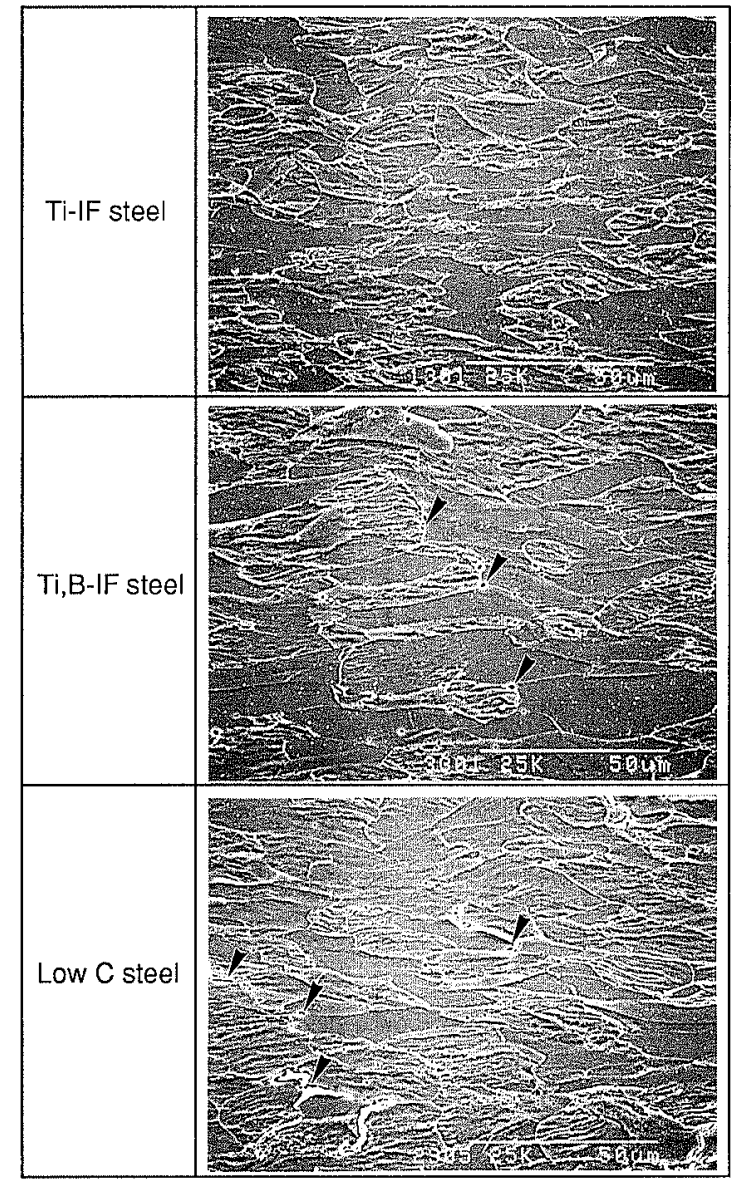

Fig. 10. SEM micrographs showing the effects of small amounts of boron and carbon segregated at grain boundaries on the microstructural inhomogeneity in deformed matrix in steels- 1 to 3 .

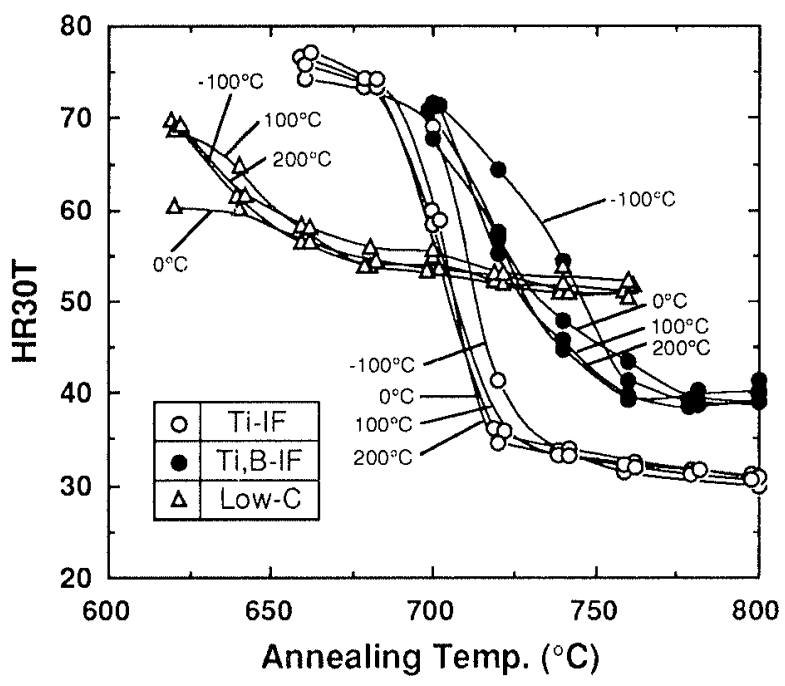

Fig. 11. Effects of cold-rolling temperature on the hardness change during recrystallization in steels-1 to 3 .

\subsection{Recrystallization Texture Formation during Anneal- ing}

Figure 11 shows the effects of cold-rolling temperature on the hardness change during recrystallization in steels-1 to 3 . Recrystallization is retarded in the IF steels compared with low $\mathrm{C}$ steel. The retardation of recrystallization in IF steel has been interpreted due to an pinning of large-angle grain boundary migration by

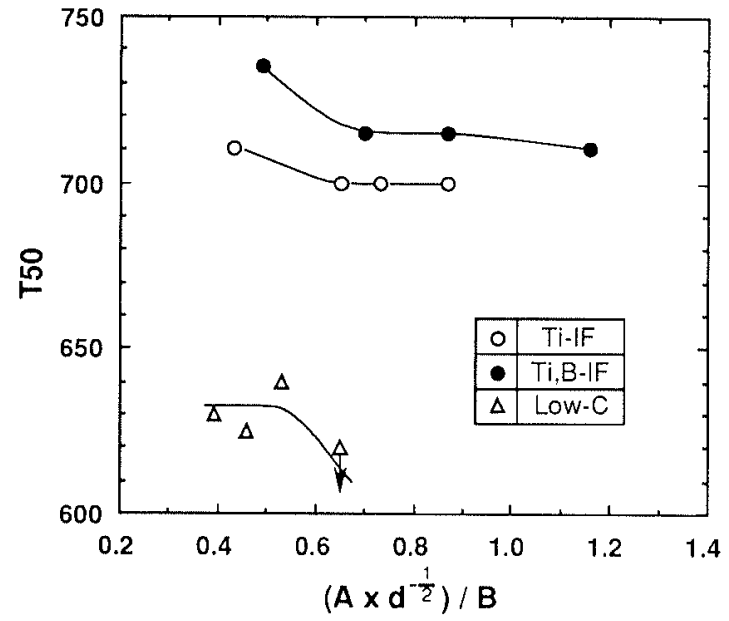

Fig. 12. Change in the half recrystallization temperature as a function of $\left(A \times d^{-1 / 2}\right) / B$ in steels- 1 and 2.

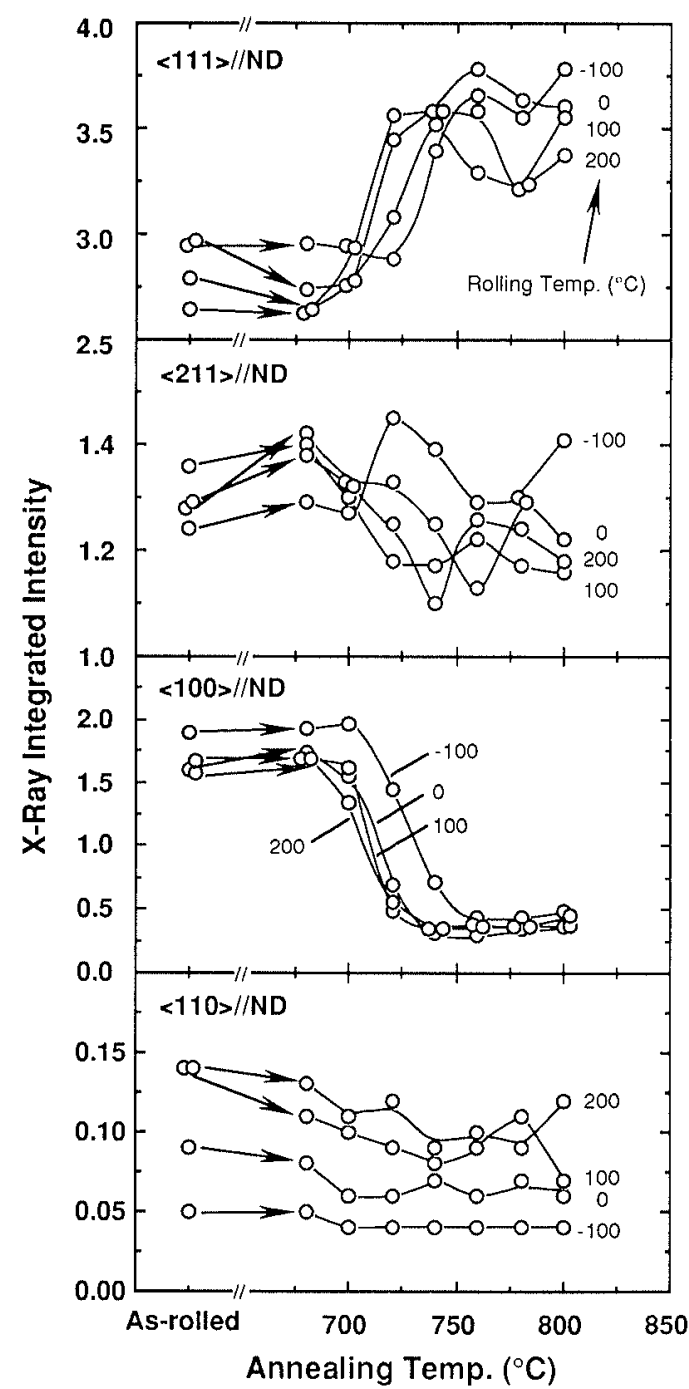

Fig. 13. Change in $\langle 111\rangle / / \mathrm{ND},\langle 100\rangle / / \mathrm{ND},\langle 211\rangle / / \mathrm{ND}$ and $\langle 110\rangle / / \mathrm{ND}$ fiber textures as a function of annealing temperature in Ti-IF steel.

particle dispersion. ${ }^{9)}$ In the IF steels, recrystallization curves shift toward higher temperature by lowering the cold-rolling temperature and are also retarded and becomes sluggish by microalloying of boron. In the low $\mathrm{C}$ steel, recrystallization is enhanced by cold-rolling at $0^{\circ} \mathrm{C}$ corresponding to the maximum $\sigma_{\mathrm{GB}} / \sigma_{\mathrm{GM}}$. Figure 12 
shows the change in the half recrystallization temperature as a function of $\left(A \times d^{-1 / 2}\right) / B$. This result suggests that the increase in $\left(A \times d^{-1 / 2}\right) / B$ enhances a nucleation of recrystallized grain inside the dark etched grains shown in Fig. 8.

Recrystallization texture formation as a function of annealing temperature in Ti-IF steel is shown in Fig. 13. Recrystallization texture inherits the $\langle 111\rangle / / \mathrm{ND}$, $\langle 100\rangle / / \mathrm{ND},\langle 211\rangle / / \mathrm{ND}$ and $\langle 110\rangle / / \mathrm{ND}$ fiber textures from the cold-rolling texture. In particular, the effect of cold-rolling temperature on the $\langle 110\rangle / / \mathrm{ND}$ fiber texture is directly reflected on its intensities in the recrystallization texture. The $\langle 100\rangle / / \mathrm{ND}$ grains are consumed with progress in recrystallization. Marked reduction in the intensity of $\langle 111\rangle / / \mathrm{ND}$ fiber texture at the early stage of recrystallization as experienced in a low $\mathrm{C} \mathrm{steel}^{18)}$ is hardly observed in the IF steels. The $\gamma$-fiber texture develops with the declines of $\langle 100\rangle / / \mathrm{ND},\langle 211\rangle / / \mathrm{ND}$ fiber textures.

Figure 14 shows the difference in the $\langle 111\rangle / / \mathrm{ND}$, $\langle 100\rangle / / \mathrm{ND}$ and $\langle 110\rangle / / \mathrm{ND}$ fiber textures formation during recrystallization in the steels- 1 to 3 cold-rolled at $0^{\circ} \mathrm{C}$. Comparing the early recrystallization texture formation with the cold-rolling texture, it is obvious that the IF steels recrystallize with inheriting the intensities of each component in the cold-rolling texture (in-situ like), while low $\mathrm{C}$ steel recrystallize with nucleating the preferred oriented grains (oriented nucleation like).

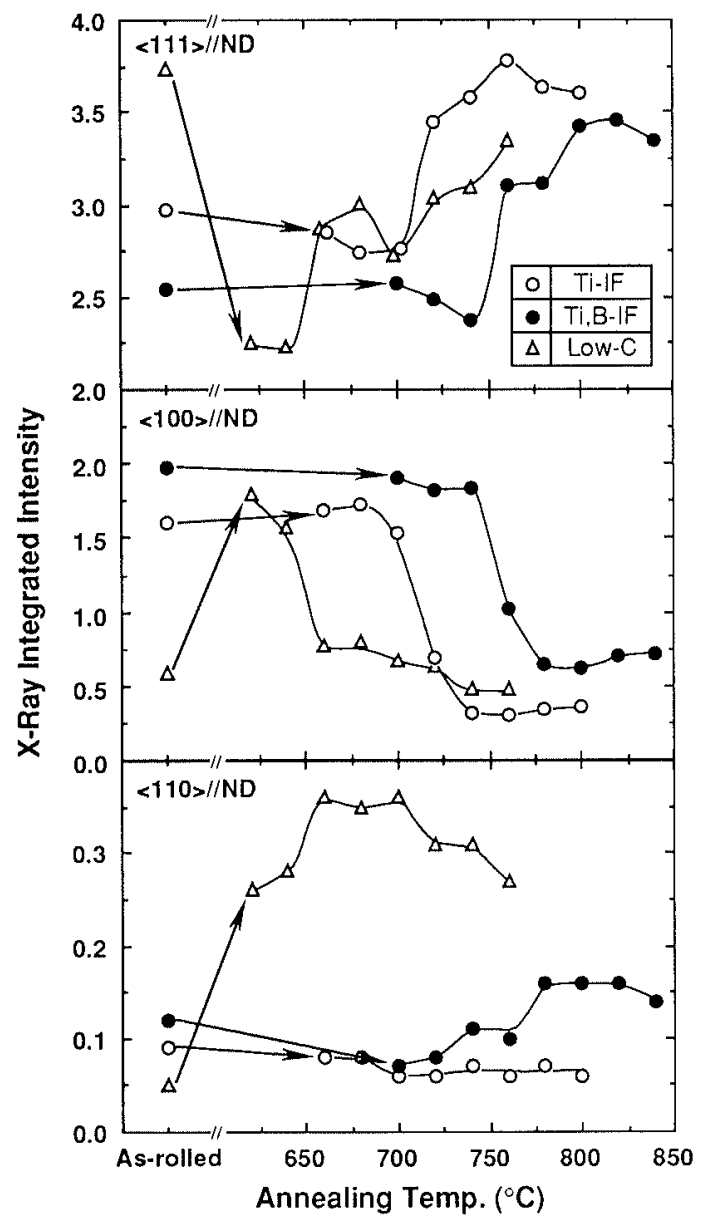

Fig. 14. Difference in the recrystallization texture formation in the steels- 1 to 3 cold-rolled at $0^{\circ} \mathrm{C}$.
Despite that the intensity of $\langle 110\rangle / / N D$ component in low $\mathrm{C}$ steel is lower than the IF steels' in as cold-rolled sheet, it develops up to about sextuples after recrystallization in low $\mathrm{C}$ steel while it scarcely change in the IF steels. Even in the IF steels, $\langle 110\rangle / / \mathrm{ND}$ fiber texture develops by microalloying of boron. In the low $\mathrm{C}$ steel, $\langle 111\rangle / / \mathrm{ND}$ component markedly decreases with the nucleation of $\langle 110\rangle / / \mathrm{ND}$ and $\langle 100\rangle / / \mathrm{ND}$ grains. These results suggest that $\langle 110\rangle / / \mathrm{ND}$ and $\langle 100\rangle / / \mathrm{ND}$ grains nucleate at the D.B. and the vicinities of grain boundaries and coarse carbide, respectively, those of which are highly strained regions.

The decline of $\langle 111\rangle / / N D$ fiber texture at the early stage of recrystallization in low $\mathrm{C}$ steel seems to be caused by a nucleation of $\{111\}\langle 110\rangle$ grains at the grain boundary area of $\{111\}\langle 112\rangle$ deformed grains. ${ }^{19)}$ Then, the conversion from the $\{111\}\langle 112\rangle$ component to the $\{111\}\langle 110\rangle$ component as a preferred orientation in the $\gamma$-fiber texture in low $C$ steel was confirmed by $\{100\}$-pole figure in contrast to the IF steels. The results are depicted in Fig. 15. The $\gamma$-fiber textures of IF steels and low $\mathrm{C}$ steel are composed of $\{111\}\langle 112\rangle$ and $\{111\}\langle 110\rangle$ preferred orientations, respectively, while the cold-rolling textures of these steels were similar as shown in Fig. 7.

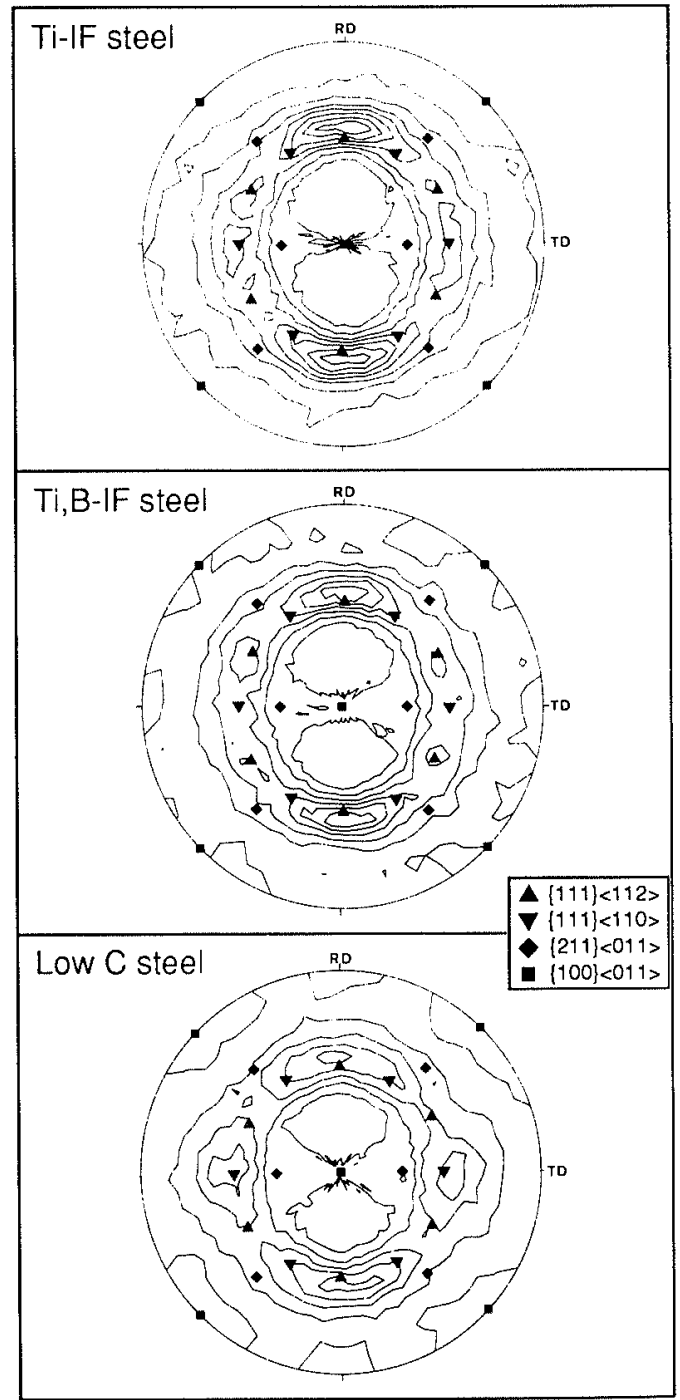

Fig. 15. Typical $\{100\}$-pole figures showing recrystallization textures of steels-1 to 3 . 

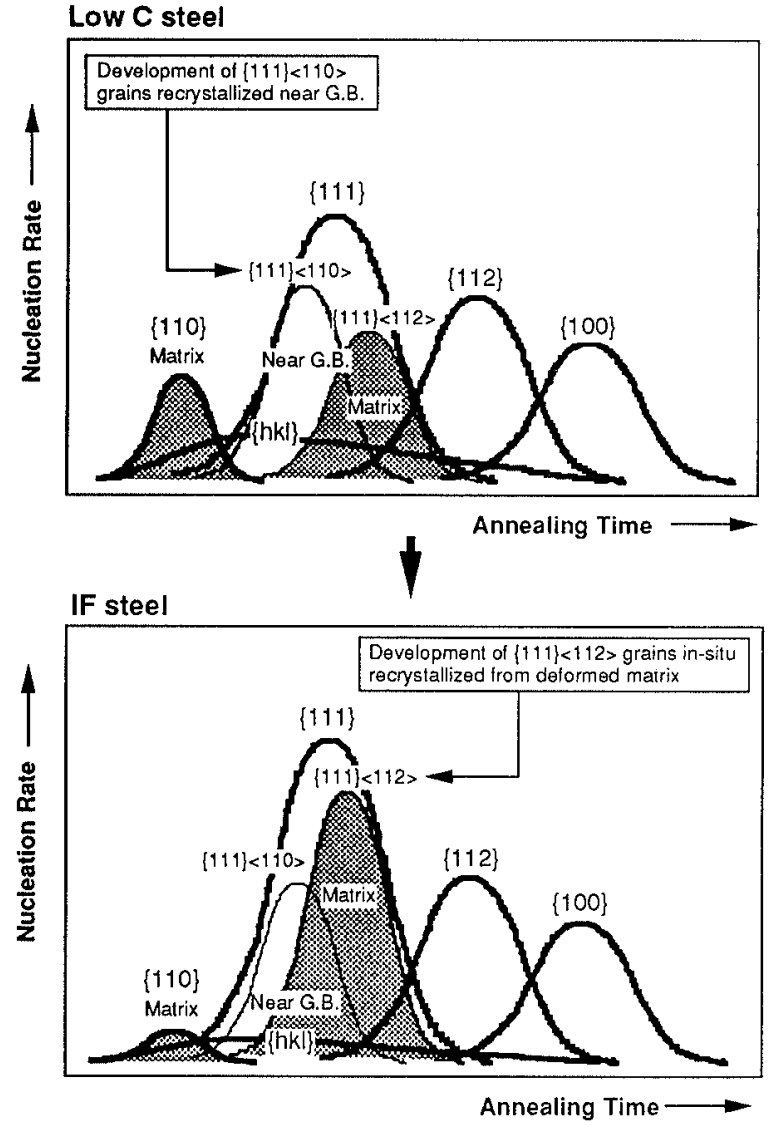

Fig. 16. Schematic representation of nucleation priority of recrystallized grains during annealing in both low carbon steel and IF steel.

\subsection{Mechanism on the Recrystallization Texture Forma- tion in IF Steel}

From the above results, in the IF steel, the $\gamma$-fiber texture declines with a development of $\langle 110\rangle / / N D$ fiber texture by not only boron addition but also elevating the cold-rolling temperature within the limits of -100 to $200^{\circ} \mathrm{C}$. Origin of these texture change is considered to be caused by increase in the strength of grain boundary constraint during cold-rolling. It has been revealed that the D.B. generated inside the $\{111\}\langle 112\rangle$ deformed grain in the cold-rolled sheet provided a nucleation site of $\{110\}\langle 001\rangle$ grain. ${ }^{20,21)}$ Therefore, the intensity of $\langle 110\rangle / / \mathrm{ND}$ component depends on the density of D.B. inside the deformed grain. Both D.B. and grain boundaries provide nucleation sites of recrystallized grain because they are highly strained and accumulating a stored-energy. Inagaki ${ }^{19)}$ revealed that the $\{111\}\langle 011\rangle$ grains nucleated at the grain boundary area of $\{111\}$ $\langle 112\rangle$ deformed grain in low $\mathrm{C}$ unalloyed steel. This process suggests that a driving force for the nucleation of $\{111\}\langle 011\rangle$ grain is larger than the in-situ recrystallization of $\{111\}\langle 112\rangle$ grain from $\{111\}\langle 112\rangle$ deformed matrix. This change in the components in the $\gamma$-fiber texture agrees with the recrystallization texture formation in low $\mathrm{C}$ steel as shown in Fig. 14. The reason for the suppression of the in-situ nucleation of $\{111\}\langle 112\rangle$ grains from $\{111\}\langle 112\rangle$ deformed matrix in the low $\mathrm{C}$ steel is considered as illustrated in Fig. 16. Since the nucleation frequency of $\langle 110\rangle / / \mathrm{ND}$ grain is the highest among other components, highly deformed

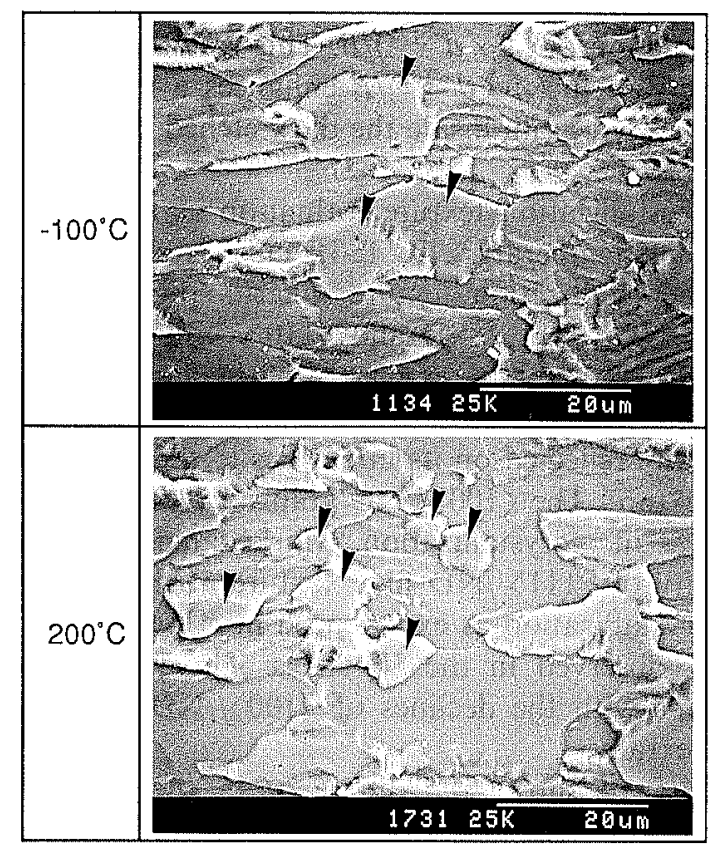

Fig. 17. SEM micrographs showing the effect of cold-rolling temperature on the nucleation site of recrystallized grains in Ti-IF steel.

grains with $\{111\}<112\rangle$ orientation which includes a lot of D.B. are ready to recrystallize quickly. Despite that the density of $\langle 110\rangle / / \mathrm{ND}$ grain in the recrystallization texture is low as shown in Fig. 14, nucleation of $\{110\}\langle 001\rangle$ grain probably consumes the stored-energy accumulated in $\{111\}\langle 112\rangle$ deformed matrix and causes a reduction of driving force for the in-situ recrystallization of $\{111\}<112\rangle$ grain.

As generally known, on the contrary, $\{111\}\langle 112\rangle$ texture markedly develops in the IF steel. From Figs. 8, 9 and 10 , it was suggested that the ferrite grains of IF steel deform homogeneously during cold-rolling caused by a reduction in the strength of grain boundary constraint through a scavenging of interstitial elements from the grain boundary. In the IF steel, therefore, stored-energy might be accumulated homogeneously in the deformed matrix independent of the heterogeneity of the microstructure, which causes the decline of the selective nucleation. Weakening of the grain boundary constraint also reduces the generation frequency of D.B. inside the deformed matrix, which suppresses the nucleation and growth of $\{110\}\langle 001\rangle$ grains from D.B. Consequently, the in-situ recrystallization of $\{111\}\langle 112\rangle$ grain can develop from the $\{111\}\langle 112\rangle$ deformed matrix as illustrated in Fig. 16.

In order to confirm the dependency of nucleation process of recrystallized grain on the strength of grain boundary constraint during cold-rolling, the morphology of recrystallized grains nucleated from the deformed matrix by annealing at $700^{\circ} \mathrm{C}$ for $90 \mathrm{sec}$ after cold-rolling at -100 and $200^{\circ} \mathrm{C}$ were observed at transversal cross section by SEM. Results are depicted in Fig. 17. In the sample cold-rolled at $-100^{\circ} \mathrm{C}$, recrystallization promptly occurred throughout the deformed grains. However in the sample cold-rolled at $200^{\circ} \mathrm{C}$, fraction of small recrystallized grains nucleated at the boundaries of 


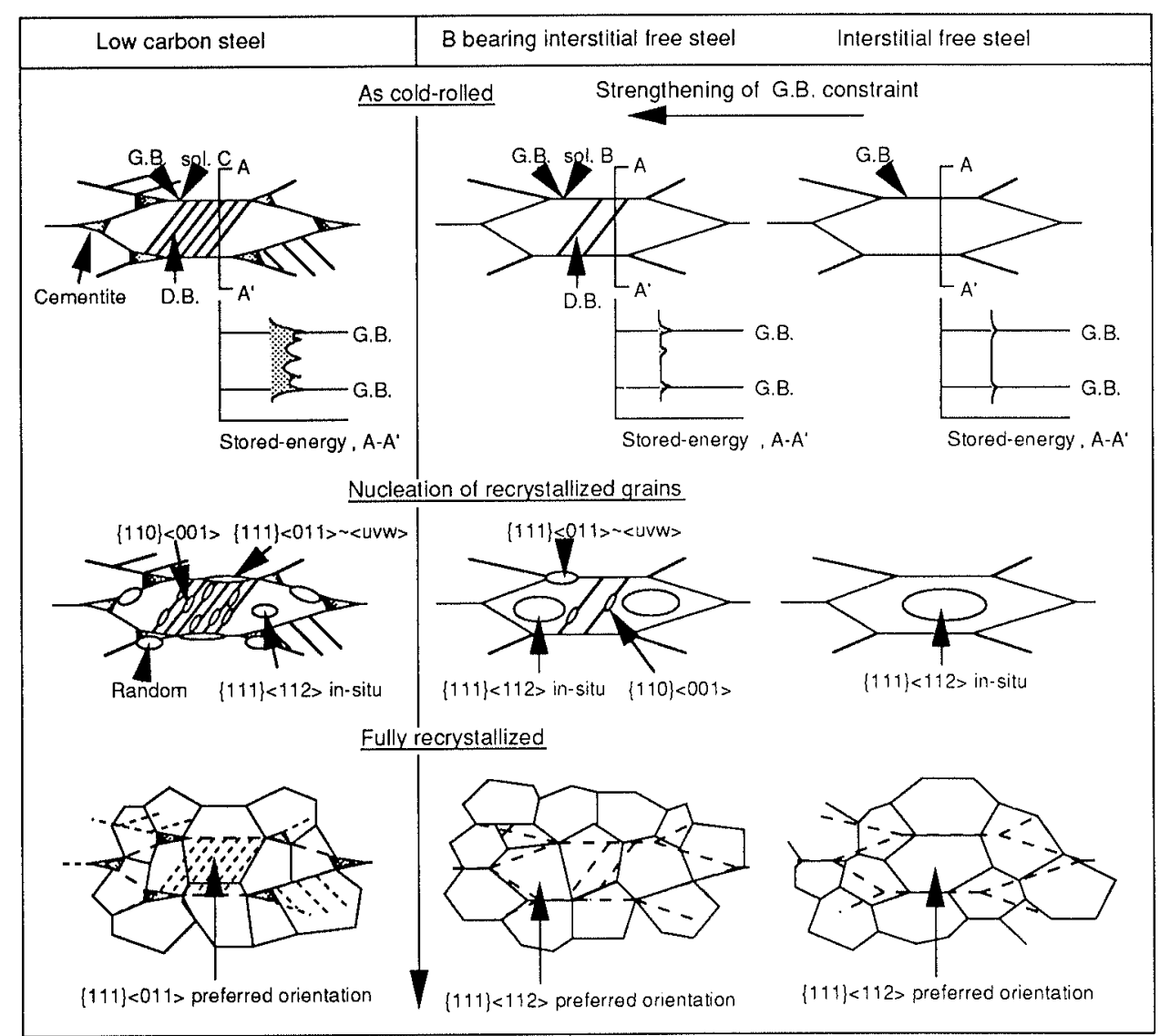

Fig. 18. Schematic diagram showing the mechanism for the recrystallization texture formation in the IF steel.

deformed grains increased. Above change in the morphology of early recrystallized grain suggests that the occurrence of in-situ recrystallization in IF steel is influenced by a reduction in the strength of grain boundary constraint.

In particular, since the cold-rolling texture of IF steel includes relatively high density of $\langle 100\rangle / / \mathrm{ND}$ and $\langle 211\rangle / / \mathrm{ND}$ components as indicated in Fig. 5, the $\{111\}\langle 112\rangle$ texture probably develops by consuming these grains during recrystallization in IF steel.

According to the above discussion, the mechanism for the recrystallization texture formation in IF steel is schematically represented in Fig. 18. The mechanism for the recrystallization texture formation in IF steel is also suggested from the fact that the recrystallization texture of IF steel was predictable in terms of selective growth theory in which nuclei possessing favorable $\langle 110\rangle$ axis rotation relationship with respect to the deformed matrix undergo preferential growth without taking the contribution of grain boundaries into consideration. ${ }^{22)}$

Microalloying of boron into IF steel, the purpose of which is strengthening the grain boundaries to improve the secondary work embrittlement, enhances the nucleation of $\langle 110\rangle / / \mathrm{ND}$ grains and weaken the $\gamma$-fiber texture through the increase in the strength of grain boundary constraint by segregated boron.

\section{Conclusion}

The main findings of this investigation and the origin of the recrystallization texture formation in IF steel are summarized as follows.

(1) Relative grain boundary constraint $\left(\sigma_{\mathrm{GB}} / \sigma_{\mathrm{GM}}\right)$ evaluated by the ratio of deformation strengths of grain boundary $\left(\sigma_{\mathrm{GB}}\right)$ and grain matrix $\left(\sigma_{\mathrm{GM}}\right)$ is increased with elevating the cold-rolling temperature within the range from -100 to $200^{\circ} \mathrm{C}$ in IF steel. $\sigma_{\mathrm{GB}} / \sigma_{\mathrm{GM}}$ of IF steel is also increased by microalloying of boron.

(2) In the cold-rolling texture of IF steel, $\langle 111\rangle / / \mathrm{ND}$ $(\gamma$-fiber) texture weakens and $\langle 110\rangle / / \mathrm{ND}$ fiber texture conversely develops with elevating the cold-rolling temperature. Microalloying of boron into IF steel enhances the above tendency. Good correlations are observed between the intensities of $\langle 110\rangle / / \mathrm{ND}$ and $\langle 111\rangle / / \mathrm{ND} \gamma$-fiber textures and $\left(A \times d^{-1 / 2}\right) / B$. Microalloying of boron into IF steel enhances the development of $\langle 110\rangle / / \mathrm{RD}(\alpha$-fiber) texture.

(3) Regarding the recrystallization texture formation, IF steel recrystallizes with inheriting the intensities of every fiber textures in the cold-rolling texture (in-situ like), while low $\mathrm{C}$ steel recrystallizes with nucleating the preferred oriented grains (oriented nucleation like). Recrystallization temperature is lowered with increase in the $\sigma_{\mathrm{GB}} / \sigma_{\mathrm{GM}}$.

(4) The $\gamma$-fiber textures of IF steel and low C steel are composed of strong $\{111\}\langle 112\rangle$ and $\{111\}\langle 110\rangle$ preferred orientations, respectively, while the cold-rolling textures of these steels were similar. Microalloying of boron into IF steel enhances the nucleation of $\langle 110\rangle / /$ ND grains and weaken the $\gamma$-fiber texture through the strengthening of grain boundary constraint by segregated boron. 
(5) Mechanism of recrystallization texture formation in IF steel is considered as follows: Ferrite grains of IF steel are deformed homogeneously during cold-rolling independent of the heterogeneity of the microstructure due to weakening of grain boundary strength by scavenging interstitial elements from the grain boundaries. Weakening of the grain boundary strength also reduces the formation of deformation bands, which is the nucleation site of $\langle 110\rangle / / N D$ grain, inside the $\{111\}\langle 112\rangle$ deformed matrix. Consequently, the in-situ recrystallization of $\{111\}<112\rangle$ grain can develop from the $\{111\}\langle 112\rangle$ deformed matrix by consuming $\langle 100\rangle / /$ ND and $\langle 211\rangle / /$ ND grains.

\section{REFERENCES}

1) Proc. Int. Conf. on Metallurgy of Vacuum-degassed Steel Products, ed. by R. Pradhan, TMS, Indianapolis, (1989), 43

2) Proc. Int. Conf. on Interstitial-Free Sheet Steel: Processing, Fabrication and Properties, ed. by L. E.Collins and D. L. Barager, CIM, Ottawa, (1991).

3) Int. Forum Book on Physical Metallurgy of IF Steels, ISIJ, Tokyo, (1994).

4) R. H. Goodenow and J. F. Held: Metall. Trans., 1 (1970), 2507.

5) P. R. Mould and J. M. Gray: Metall. Trans., 3 (1972), 3121

6) R. E. Hook, A. J. Heckler and J. A. Elias: Metall. Trans., 6A (1975), 1683.
7) N. Fukuda and M. Shimizu: Trans. Iron Steel Inst. Jpn., 17 (1977), 339.

8) H. Hayakawa, Y. Furuno, M. Shibata and N. Takahashi: Trans. Iron Steel Inst. Jpn., 23 (1983), B434.

9) D. O. Wilshynsky, G. Krauss and D. K. Matlock: Proc. Int. Conf. on Interstitial-Free Sheet Steel : Processing, Fabrication and Properties, ed. by L. E. Collins and D. L. Barager, CIM, Ottawa, (1991), 69.

10) B. Hutchinson and E. Lindh: Int. Forum Book on Physical Metallurgy of IF Steels, ISIJ, Tokyo, (1994), 127.

11) T. Obara, S. Satoh, M. Nishida and T. Irie: Scand. J. Metall., 13 (1984), 201.

12) Y. Hosoya, T. Suzuki and A. Nishimoto: Proc. Int. Conf. on Metallurgy of Vacuum-degassed Steel Products, ed. by R. Pradhan, TMS, Indianapolis, (1989), 29I.

13) S. Suzuki, M. Obata, K. Abiko and H. Kimura: Trans. Iron Steel Inst. Jpn., 25 (1985), 62.

14) W. C. Leslie: The Physical Metallurgy of Steels Int., McGraw Hill, (1982), 126.

15) T. Ohue, H. Takechi and Y. Furuno: J. JSTP, 28 (1987), 225.

16) H. Inagaki: Z. Metallkd., 79 (1988), 164.

17) D. Vanderschueren: Int. Forum Book on Physical Metallurgy of IF Steels, ISIJ, Tokyo, (1994), 145.

18) W. B. Hutchinson: Int. Metals Rev., 29 (1984), 25.

19) H. Inagaki: Z. Metallkd., 78, (1987), 431.

20) M. Abe and K. Ushioda: Tetsu-to-Hagané, 70 (1984), Al08.

21) L. Seidel and K. Lucke: Texture in Silicon Steel, Texture and Microstructure, (1991), 903.

22) T. Urabe and J. J. Jonas: Trans. Iron Steel Inst. Jpn., 34 (1994), 435. 